\title{
Service user, patient, survivor or client has the time come to return to 'patient'?
}

\author{
David M. B. Christmas/Angela Sweeney
}

\section{Summary}

Recently, the Council of the UK Royal College of Psychiatrists agreed to use the term 'patient' as the preferred collective noun when referring to people accessing mental health services in its official documentation. Choices regarding terminology have the power to influence those who use such terms and here, David Christmas and Angela Sweeney debate the issue of whether such a decision is appropriate or whether we need to be more careful about the terms we use.

\section{Declaration of interest}

D.M.B.C.: None./A.S.: None.

\section{Copyright and usage}

(c) The Royal College of Psychiatrists 2016.

\section{For}

\section{Terminology is important but we should be democratic}

In 2013 the Council of the UK Royal College of Psychiatrists decided, for the purpose of College documents and reports, to adopt the term 'patient' as the preferred collective noun for people accessing mental health services. In order to underline the importance of parity between mental and physical health, a common term is important. In addition, alternative terms for people with mental health problems do not appear to reduce stigma and many people find the term 'user'/'service user' to be actively stigmatising. Finally, the term 'patient' has been used for so long and is recognised internationally.

Such arguments are undermined if alternative terms have a mandate from those to whom the term applies. This is not the case, however. It is likely that some of the reasons that people are arguing for a change (away from 'patient') include the same desire for a recognised voice that have driven the corresponding social movements such as 'normalisation'. I raise no argument against the importance of these social movements, but I will suggest such movements do not automatically reflect the wishes of those they presume to represent.

\section{History of terminology}

Prior to the 1960s self-support groups usually used the term 'patients'. In the 1970s and 1980s, however, US mental healthcare began to transform. Large institutions failed to deliver meaningful care for those who entered them but subsequent deinstitutionalisation led to fragmented care that did not meet the needs of many people.

The origins of 'recovery' as a coherent set of values also occurred at roughly the same time that recipients of care became active users of services. 'Recovery' started to be owned by individuals (rather than health professionals) and people began to see the reform of mental health services as a social movement. These social movements also generated a degree of radicalisation of the ex-patient movement.

In recent years, as mental healthcare has adapted to changing social systems and values, most mental health groups have become less radicalised and in the past decade we have seen such groups (for example charities and carer groups) engaging constructively with politicians and healthcare services to improve care using a common dialogue. So, is such a radicalised terminology (asserting difference and a unique identity) still necessary?

I would suggest that the majority of people with mental illness have not consented to a radical shift in terminology. Rather, many of the terms in current use actually reflect the sociopolitical aspirations of an unrepresentative vocal minority whose quasipolitical agenda extends beyond the simple aim of improved mental healthcare.

\section{What does being a 'patient' actually mean?}

Historically, the term 'patient' came to be seen as reflecting passivity and disempowerment, whereas 'survivor' and 'client' (which, ironically, derives from the Latin cluere - to hear, follow or obey) represented a more empowered view of interaction with their healthcare services. For most people, however, 'patient' confers no negative associations. It simply refers to anyone seeking and/or receiving healthcare. The word in itself neither implies nor evokes passivity - it derives from the Latin word 'patiens', which means 'to suffer', but usage can be independent of symptom burden.

Most people are already familiar with concepts such as 'patient confidentiality' or the 'doctor-patient relationship'. Importantly, the term does not discriminate between physical and mental health: when Scotland passed the Patient Rights (Scotland) Act 2011, it recognised no need to discriminate between those with physical health problems and those with mental health problems. Everyone was entitled to the same rights regardless of their healthcare needs. It seems unnecessary to suggest that more than one term is required when referring to a common set of rights and values.

\section{Stigma}

One can legitimately argue that it is foolish to argue for parity of esteem between mental and physical health when the language used to refer to those with such conditions is different. When everyone is a 'patient', people are considered equal but 'service users' are automatically identified as experiencing mental illness by virtue of their collective noun. The irony is that in attempting to resist the imposition of titles onto the unwilling, those who advocate 'service user' are deliberately imposing upon others a term that most people do not identify with or want. 


\section{What does the evidence say?}

A number of studies have been conducted that answer the important question: what do people who receive mental healthcare want to be called? ${ }^{1-11}$ These studies have collectively polled 4369 people in five different countries: USA $(n=2204)$, UK $(n=979)$, Poland $(n=634)$, Canada $(n=427)$ and Australia $(n=125)$. Although there are some caveats (not all studies compared the same terms in the same populations, for example) the answer is almost certainly 'patient' and it is assuredly not 'service user'.

To summarise these findings: $42.7 \%$ of 4369 people endorsed 'patient', $31.3 \%$ endorse 'client' and $12.5 \%$ endorsed other specific terms. Interestingly, only $3.1 \%$ endorsed 'service user' and only $6.5 \%$ endorsed 'survivor'. The overwhelming majority of people appeared to prefer the term 'patient' whereas only 1 in 33 people chose to be called 'service user'. With regards to regional differences, a higher number of people in the USA preferred the term 'client' (UK 30.8\%; USA 38.7\%) and/or 'consumer' (UK $0 \%$; USA $13.3 \%$ ) to 'patient' (UK 60.9\%; USA 23.8\%). Canada and Poland appeared more closely aligned to the UK, and Australia mirrored the USA. A recent systematic review arrived at similar conclusions. ${ }^{12}$ It is unknown whether preference for 'service user' will increase over time, but given what we know about people's preferences currently, why would we use a term that $97 \%$ of people who use mental health services throughout the world do not endorse?

\section{Conclusions}

Usage of the term 'service user' commits the very same 'offence' that such advocates are apparently protesting: defining a group solely by the presence of a mental illness. Ironically, by trying to break free from the perceived shackles of medical paternalism, people have chosen a vocabulary that defines people entirely by their usage of a specific type of healthcare. Equally importantly, 'service user' is not a term that people would choose when you ask them. 'Patient' may not be the perfect term, but 'service user' is already being criticised by those who are clearly not advocates of the medical model (whatever that actually is). ${ }^{13,14}$

If we were serious about listening to the voices of people receiving input from mental health services, and if we seriously wished to empower those who are expressing a preference, the term 'service user' would vanish. Anything else is simply the kind of oppression that those who advocate the term are wishing to extinguish. Although this debate has continued for over 20 years, the conclusions of Upton (1994) have yet to be contradicted: 'We should be wary about abandoning a term favoured by those to whom it refers.'

David M. B. Christmas

\section{Against}

\section{Whose terminology, whose democracy?}

You (D.M.B.C.) defend the UK Royal College of Psychiatrists' decision to revert to the term 'patient'. I will first respond to your main arguments and in particular, your use of psychiatric research to suggest a consensus of opinion. I will then outline some key arguments against the College's decision including that: the decision furthered the interests of the College and undermined the right to self-identity developed by the survivor movement; the medicalisation of mental distress creates rather than dispels stigma; and where possible, people should be called people. As Oaks states 'Words matter, especially when they have the force of law. ${ }^{15}$

\section{The evidence}

The 'evidenced' component of your argument rests on surveys of preferences for terms used to describe people using psychiatric services which, you claim, demonstrate that people want to be called patients - anything else would be undemocratic. However, a systematic review of these surveys described them as methodologically weak: research teams devise their own questionnaires with little evidence of piloting; the reliability, validity or acceptability of questionnaires is not established; there is no attempt to control for response bias; there is no service user involvement to ascertain appropriateness; and there is no consistency in the terms people choose between, with many studies not offering 'service user' as an option. ${ }^{12}$ These studies are not democratic. They are conducted by clinical teams of local populations without the involvement of the people that the surveys are about. Such methodological flaws will have affected the reported findings. The review identified that the highest quality studies find that people prefer the term 'client' over 'patient' (although possibly because these studies have been conducted in North America where 'client' is commonplace). ${ }^{12}$ The main factor influencing preference is site, with people on in-patient wards typically preferring 'patient' to those in the community. ${ }^{9,11}$ This makes sense given the compulsory context of in-patient wards: knowing that treatment is delivered within a legal framework that enables compulsion affects everyone, voluntary or involuntary. ${ }^{16}$ Terms like 'client' and 'consumer' imply choice, and people may feel they are far from 'surviving'. Thus, choosing to describe the relationship on a ward as one of doctor-patient does not imply an uncritical acceptance of either the label or the relationship. Moreover, how a person chooses to be described by their practising clinician within a clinical encounter and how they self-define more broadly may not be synonymous.

Some surveys found that people's choice of term is heavily influenced by the preferred term of health professionals in the service they are using. ${ }^{9,11}$ Thus, survey findings - and the debate around terminology - can be self-fulfilling and tautological. Health professionals, particularly psychiatrists, have the power to set the discourse. When people using services adopt that discourse, as in the case of preferring the terminology that is used by your service, it may be because that is how people have been taught to speak about mental health. ${ }^{17}$ To say that any other discourse is undemocratic is to fail to understand and reflect on the power of the psychiatric discourse and one's role within it. In essence, calling people patients, then stating that people call themselves patients and that therefore patient is evidently the best terminology, is mere tautology.

The systematic review also found that although UK surveys demonstrate a preference for 'patient', this appears to be declining over time, but the poor quality of studies means that conclusions are not possible. ${ }^{12}$ The most recent survey of people who experience mental distress conducted by the Scottish Recovery Network found a strong preference for 'people who ...' or 'people affected by . . ., , with little preference for patient ( $17 \%$ selected patient as their preferred term and it was ranked sixth out of ten terms). ${ }^{10}$ Notably, this is the only survey you cited that was conducted by people who experience mental distress.

\section{A lack of consensus and the role of survivor movements}

Far from demonstrating consensus, these surveys reveal - and often explicitly refer to - a lack of universality. ${ }^{9}$ There is clearly no consensus on acceptable nomenclature. ${ }^{18,19}$ Moreover, there is no evidence demonstrating a split between the 'vocal minority' 
in the survivor movement and the people that psychiatrists see in clinics. Crepaz-Kaey has described 'the "articulate user" syndrome' whereby people who gain the confidence to speak out have their views dismissed as unrepresentative of 'ordinary' service users. ${ }^{20}$ To paraphrase Viv Lindow, this means we are encouraged to have a voice right up to the point where we find one. Moreover, the survivor movement embodies a participatory rather than representative form of democracy. ${ }^{21}$ You are dangling a red herring in resurrecting the 'representativeness' debate.

Within and beyond the survivor movement people selfidentify in a variety of ways, described by Vanessa Jackson:

'language is important and political. Those of us who have been labelled by the psychiatric community have been denied a choice in how we are presented to the world. Through our liberation struggles, we have created our own identities as consumers, survivors and ex-patients, users and recipients'.22

Describing oneself as a patient, consumer, service user, survivor, service refuser or inmate defines how we see ourselves in relation to psychiatry: what is my relationship with healthcare providers? What is the cause of my distress? To whom do I turn when in crisis? What helps me heal? The label 'is descriptive not of a person but of a relationship. ${ }^{14}$ Within an individual, self-identity may change over time, depending on how we are making meaning from our experiences and conceptualising madness and the role of psychiatry.

You have assumed that the vocal minority of the survivor movement undemocratically imposes terms on the silent majority who want to be called 'patient'. Not so. Rather than adopting a single position, the survivor movement embraces the right to self-identify. Inclusive terms are often used such as service user/ survivor in the UK and consumer/survivor/eX-patient or $\mathrm{c} / \mathrm{s} / \mathrm{x}$ in North America. Reaume has described this proliferation and complexity of terminology as the 'democratization of mass selfidentity.'. ${ }^{18}$ Thus, when the Royal College of Psychiatrists reverted to the term 'patient', far from being democratic, they undermined the democratisation of self-identity forged by the survivor movement.

\section{Why has the Royal College of Psychiatrists adopted the term 'patient'?}

When there was an opportunity to be progressive and to engage in debate, why instead did the College decide to revert to the term 'patient'? It is possible that it represented a marker in the sand: it signifies the College's continued belief in the biomedical model of mental illness. It designates psychiatry as a medical discipline with equal status to physical health. It implicitly describes the psychiatrist as healer and protector of the sick. It reasserts psychiatry's right to jurisdiction over those who are othered, particularly where they are seen as lacking the insight to comply. Similarly, it has been claimed that the historic shift from 'lunatic' to 'patient' and 'asylum' to 'hospital' in the 1900s served the social, medical and legal functions of enhancing psychiatrists' professional status, promoting scientific models of mental distress and ensuring psychiatric jurisdiction over madness. ${ }^{18}$ You state that the College's decision was partly because 'patient' has been used for a long time and is recognised internationally. It seems more than a little unjust to exclaim, 'but this is what we've always called you.'

\section{Call people, people}

It is this construction of mental distress as mental illness that creates stigma and discrimination. This is because it 'others', creating the perception of a clear dividing line between the sick and the sane. ${ }^{23}$ There is strong and growing evidence for the causal role of trauma in mental distress. ${ }^{24}$ Understanding the impact of abuse, violence, inequality and racism means that mental distress becomes social, something that can happen to us all, something that collectively we can change.

You claim that alternative terms to patient do not reduce stigma, and that 'service user' is actively stigmatising because it defines a group solely by their use of services, whereas all of us are patients. No, not all of us are mental patients. And 'service user' defines a group by its use of services, not by a sick role. The current momentum is to call people 'people' wherever possible. This questions and reduces difference, demonstrates that mental distress is part of the human condition, ensures we listen to people's life stories rather than seek explanations in genetics or neurology, and means our complex identities and humanity are no longer reduced to a sick role, or to a single, all-defining component.

\section{Embrace the democratisation of self-identity}

It is not insignificant that the Royal College of Psychiatrists' decision occurred at a moment in time when people's claims to our own knowledge, truth, meaning-making, identity and rights are growing louder. So what could the College have done? They could have embraced the complexity of language and the democratisation of mass self-identity by engaging in debate: as Oaks states, 'This fascinating, frustrating, ongoing discussion is in fact the solution. ${ }^{15}$ By failing to embrace debate, the College missed an opportunity to move beyond the monolithic bio-bio-bio model and engage with the voices of people who are deeply affected by its decisions. The survivor movement has long embraced the democratisation of mass self-identity; it is time that the College did the same.

Angela Sweeney

\section{For: rebuttal}

You (A.S.) seem to have misinterpreted some of my statements. First, I did not suggest that there was a 'consensus of opinion'; quite the contrary. However, I would argue that we need to be mindful of the majority of views; hence my references to the importance of democratic opinion-forming. Second, although I would freely acknowledge some of the limitations of the evidence, short of declaring a systematic conspiracy by the establishment, the evidence is compelling: when you ask people, the majority are happy with the term 'patient'.

You appear overly concerned with the quality of the evidence. However, the suggestion that these studies were somehow imposed on recipients is incorrect. The majority are simple surveys. A detailed examination of reasons why pilot studies were not reported is outwith this discussion, but issues of contamination and small sample sizes may have affected such decisions. But arguments that this may have invalidated simple surveys of preferences needs to be based on more than mere presumptions. Additionally, the majority of the studies I cited are less likely to be biased than the Scottish Recovery Network study ${ }^{10}$ which is, without doubt, an 'enriched' sample.

The importance of self-definition is not what is being debated here. People should be able to choose whatever label or identity they wish without fear of having this label challenged. What is being discussed is the legitimacy of a collective noun for people who experience mental illness and who have contact with psychiatric services. At the current time there is scant evidence to suggest that the term 'patient' is illegitimate. The discourse regarding how people have come to use the term 'patient' does not demonstrate tautological reasoning. One obvious possibility that you seem reluctant to consider is that the choice of term 
simply reflects the preferred term of both parties using the term. However, this realisation robs you of a battle you seem eager to fight.

The comments about participatory democracy are flawed. If you claim to speak on behalf of other people, you are obliged to assure yourself that you represent the majority of views; anything else is incompatible with basic features of democracy. Many examples of participatory democracy are associated with slow decision-making and a lack of clarity about its aims. Commentators have also described the 'fetishisation of form and process over ideology ${ }^{25}$ and many forms of participatory democracy fall foul of the problems of instrumentalism and pragmatism. ${ }^{26}$

Arguing that mental illness is some kind of 'other' (i.e. outside of mainstream medicine) runs the risk of condemning those with psychiatric illness to some kind of wilderness and it flies in the face of attempts to achieve parity. To suggest that those with mental illness should have parity (with physical illness) but that those that treat it are not entitled to the same parity is an untenable position. Worryingly, you seem to be suggesting that self-identity should trump any collective noun, regardless of the number of people who may be comfortable with that term. However, the use of a completely unrecognisable and/or rarely-used term (the term 'survivor' for example was chosen by only $5.3 \%$ of UK respondents) conflicts with the suggested need to establish a group identity. A group identity with no consensus is not a stable identity.

The references to 'distress' are disingenuous. First, most psychiatrists have no desire to impose jurisdiction over emotional states that are recognised by clinicians as being universal and usually time-limited. Second, psychiatrists understand that although distress is a common component of mental illness, it is not the same thing; in the same way that respiratory physicians would not try to assert dominion over all 'breathlessness'. By reducing severe and life-limiting illness to the same status as reactive, and time-limited states that are, essentially, 'normal' is a kind of mental illness denial that does nothing to further the causes that you are so clearly passionate about.

David M. B. Christmas

\section{Against: rebuttal}

You (D.M.B.C.) claim that I have misinterpreted you. I actually stated that you had used psychiatric research to suggest a consensus of opinion - the misinterpretation was not mine. By the by, you fundamentally misunderstood the meaning of 'other'. It is not possible to be 'overly concerned' with the quality of evidence, particularly where that evidence is being used to make grand claims. If the quality of evidence is poor, resulting claims cannot be relied upon. Thus, it has not been demonstrated that people prefer 'patient'.

Yes, a hypothetical critique of participatory democracy is possible. But our slow democratic processes have generated consensus on the democratisation of mass self-identity, and inclusive collective nouns that respect diversity and difference (service user/survivor in the UK). Which form of democracy did the Royal College of Psychiatrists engage in? Did they consult the people affected by their decisions? No: this expectation is limited to the survivor movement. It is a red herring. Similarly, the College could use an inclusive collective noun. Or 'people', or 'people who ...' ' Choosing patient is a retrograde step which: 'indicates immediately the unequal nature of the relationship and "objectifies" the person who is the user. The professional knows what to do and the recipient does as instructed. The user becomes passive, the provider becomes all knowing, all healing, all powerful'. ${ }^{27}$

Your concern with parity of esteem between psychiatry and physical health exposes your primary motivation. This is not about what we want. It is about depicting psychiatry as a legitimate medical discipline. I am not eager to fight a battle. I am keen to foster respectful discussion. Debate is vital, and is in direct contrast to the College's imposition of a collective term, without consultation.

Angela Sweeney

\section{For: conclusion}

If there is insufficient evidence to conclude that the majority prefer 'patient' (and it is the most-preferred term when combining surveys of 4369 people), the suggestion that there is a 'consensus' for 'service user' or 'survivor' is devoid of any supporting evidence. Replacing majority view with minority opinion cannot be said to be democratic, however participatory it is believed to be. It is a bit like disagreeing with the outcome of an election and suggesting that the wrong people voted.

It is important to remember that the choice of term reflects a need for a recognisable collective noun for people receiving treatment from mental health services. Those who do not have contact with mental health services are not going to be 'patients' and are free to call themselves by any name they wish. Self-identity can be independent of terms used by services. It is just that at the current time, 'patient' is the most appropriate, the mostrecognised, and most easily-recognised term for people receiving medical services.

I am not driven by the need to portray psychiatry as a 'legitimate medical discipline' - this is an entirely separate argument and I would argue that the antiquated doctrinaire anti-psychiatry tendencies of a minority are not automatically synonymous with discussions about a choice of terminology; although I expect this will be disputed.

It needs to be reiterated that this is not about 'imposing' terminology. The College has simply adopted the term that, according to the current evidence, is preferred by the majority of people. I would expect that when there is compelling evidence to suggest that terminology should change, it will. But there needs to be compelling evidence that most people prefer the term(s).

David M. B. Christmas

\section{Against: conclusion}

Again there have been misunderstandings. I did not state that there is a consensual preference for service user or survivor, but that there is no agreement regarding any collective noun. Indeed, as the highest quality evidence suggests that people favour client, and you purport to be concerned with democratic majorities, why not argue for the adoption of that term?

It is very easy to dismiss my arguments as 'anti-psychiatry'. What I have suggested is that people have the right to self-identify, that the Royal College of Psychiatrists could have used an inclusive or progressive term (such as service user/survivor, or people or 'people who ...') and that constructive debate on an equal footing is needed. I dismissed the surveys of terminological preferences because they are methodologically weak. It was not that I did not like the 'vote'; it was that the voting system was too flawed for the outcome to be valid. Moreover, you cannot meaningfully add up the number of votes when the voters have been offered different candidates.

I do not believe that my suggestions are radical. But I do believe that it is easy to dismiss survivors' views as radical or unrepresentative when it is convenient. But the inconvenient truth is there is no consensus on this or many other issues. This is 
why we need constructive debate between all concerned, not self-serving decision-making masquerading as democracy.

Angela Sweeney

For: David M. B. Christmas, MBChB, MD, MRCPsych, Advanced Interventions Service, Ninewells Hospital and Medical School, Dundee, DD1 9SY. UK. Email: david.christmas@nhs.net. Against: Angela Sweeney, MA(Cantab), PhD, St George's University of London, London, UK. Email: asweeney@sgul.ac.uk

First received 20 Mar 2015, accepted 20 Mar 2015

\section{References}

1 Upton MWM, Boer GH, Neale AJ. Patients or clients? - a hospital survey. Psychiatr Bull 1994; 18: 142-3.

2 Lloyd C, King R, Bassett H, Sandland S, Savige G. Patient, client or consumer? A survey of preferred terms. Australas Psychiatry 2001; 9: 321-4.

3 Ritchie CW, Hayes D, Ames DJ. Patient or client? The opinions of people attending a psychiatric clinic. Psychiatr Bull 2000; 24: 447-50.

4 Sharma V, Whitney D, Kazarian SS, Manchanda R. Preferred terms for users of mental health services among service providers and recipients. Psychiatr Serv 2000; 51: 203-9.

5 McGuire-Snieckus R, McCabe R, Priebe S. Patient, client or service user? A survey of patient preferences of dress and address of six mental health professions. Psychiatr Bull 2003; 27: 305-8.

6 Keaney F, Strang J, Martinez-Raga J, Spektor D, Manning V, Kelleher M, et al. Does anyone care about names? How attendees at substance misuse services like to be addressed by health professionals. Eur Addict Res 2004; 10: 75-9.

7 Simmons P, Hawley CJ, Gale TM, Sivakumaran T. Service user, patient, client user or survivor: describing recipients of mental health services. Psychiatrist 2010; 34: 20-3.

8 Anczewska M, Świtaj P, Prot K, Chrostek A, Waszkiewicz J, Indulska A. A survey to investigate the preferred terms describing people with mental disorders - recipients' and providers' opinions. Arch Psychiatry Psychother 2011; 3: 25-30.

9 Thalitaya MD, Prasher VP, Khan F, Boer H. What's in a name? - the psychiatric identity conundrum. Psychiatr Danub 2011; 23 (suppl 1): S178-81.

10 Bradstreet S. Language: What You Said and What We'll Do. Scottish Recovery Network, 2014 (http://www.scottishrecovery.net/Latest-News/ language-what-you-said-and-what-well-do.html).

11 Covell N, McCorkle B, Weissman E, Summerfelt T, Essock S. What's in a name? Terms preferred by service recipients. Adm Policy Ment Health 2007 34: 443-7.
12 Dickens G, Picchioni M. A systematic review of the terms used to refer to people who use mental health services: user perspectives. Int J Soc Psychiatry 2012; 58: 115-22.

13 Cowden S, Singh G. The 'user': friend, foe or fetish?: a critical exploration of user involvement in health and social care. Crit SoC POl 2007; 27: 5-23.

14 McLaughlin H. What's in a name: 'client', 'patient', 'customer', 'consumer', 'expert by experience', 'service user' - what's next? Br J Soc Work 2009; 39 $1101-17$.

15 Oaks D. Let's Stop Saying "Mental Illness"! MindFreedom, 2012 (http:// www.mindfreedom.org/kb/mental-health-abuse/psychiatric-labels/ not-mentally-ill).

16 Campbell, P. Challenging loss of power. In Speaking Our Minds (eds J Read and J Reynolds): 56-62. Macmillian Press, 1996.

17 Wallcraft J. Turning Towards Recovery? A Study of Personal Narratives of Mental Health Crisis and Breakdown. PhD, South Bank University, London, 2001.

18 Reaume G. Lunatic to patient to person: nomenclature in psychiatric history and the influence of patients' activism in North America. Int J Law Psychiat 2002; 25: 405-26.

19 Beresford P.'Service user': regressive or liberatory terminology? Disabil Soc 1995; 20: 469-77.

20 Crepaz-Kaey D. Who do you represent? In Speaking Our Minds (eds J Read and J Reynolds): 184-5. Macmillian Press, 1996.

21 Beresford P. Disabled people, service users, user involvement and representation. Disabil Soc 1994; 9: 315-25.

22 Jackson V. In our Own Voice: African American Stories of Oppression Survival and Recovery in Mental Health Systems. Part 3 of It's About Time: Discovering, Recovering and Celebrating Psychiatric Consumer/Survivor History. Vanessa Jackson, 2002 (http://www.power2u.org/downloads/ InOurOwnVoiceVanessaJackson.pdf).

23 Bellamy F. Time to change for Time to Change? Discursive of Tunbridge Wells 2014; 10 January (http://discursiveoftunbridgewells.blogspot.co.uk/2014/01/ flo-bellamy-does-diagnosis-simply.html).

24 Anda RF, Butchart A, Felitti VJ, Brown DW. Building a framework for global surveillance of the public health: implications of adverse childhood experiences. Prev Med 2010; 39: 93-8.

25 Penny L. Protest by consensus. New Statesman 2011; 16 October (http:// www.newstatesman.com/blogs/laurie-penny/2011/10/spain-movementsquare-world).

26 Vitale D. Between deliberative and participatory democracy: a contribution on Habermas. Philos Soc Criticism 2006; 32: 739-66.

27 Neuberger J. Let's do away with "patients". BMJ 1999; 318: 1756. 